\title{
Eco-intensity Analysis as Sustainability Indicators related to Energy and Material Flow
}

\author{
Koji Amano* and Misato Ebihara** \\ *Ritsumeikan University, amano@se.ritsumei.ac.jp \\ 1-1-1 Noji-higashi, Kusatsu, Shiga 525-8577 \\ **IBM Japan, Ltd., rv001977@ se.ritsumei.ac.jp \\ 3-2-12 Roppongi Minato-ku, Tokyo 106-8711
}

Keywords: Sustainability, Eco-intensity, Material flow analysis, Energy balance analysis

\begin{abstract}
This paper presents the results of an analysis on energy and material flow in different regions and industrial sectors of Japan to evaluate regional and industrial sustainability. Several life cycle approaches used to quantify environmental efficiency related to energy and material flows were investigated as applications of life cycle tools in emerging markets, including the service industry and public sector. The regions included all forty-seven Japanese prefectures and the data for each prefecture considered sixteen industrial categories based on the national physical distribution census and national input-output tables for 1995 . The ratio of the primary energy supply to the total material input for service industries ranged from 0.1 to 0.5 $\left[\mathrm{TOE} / 10^{3}\right.$ ton] for the forty-seven prefectures. Ultimately, several relationships between "energy/flow" and regional or industrial characteristics were derived, such as regional population, distance from major markets, and so on.
\end{abstract}

\section{INTRODUCTION}

In order to develop a sustainable society, an indicator that relates our understanding of the present state of urban metabolism to social activity is required. Studies have investigated the amount of material required based on social activity, e.g., material flow accounting (Adriaanse et al., 1997), and have included a macroscopic analysis of specific categories of material distributed among industries in Japan. Toward a future sustainable society, we must consider a kind of "Trilemma" of resources involving energy, the environment, and the economy. Sustainability indicators should ensure improved eco-efficiency, which means reduced eco-intensity. Using such sustainability indicators, we can promote regional or industrial transformation. Recent uses of sustainability indicators have been already reported for several local regions and industrial sectors. Quantitative indicators of the physical/biological aspect of sustainability could be applied to an agricultural county, using energy, water, soil, and nitrogen as numeraires (Herendeen and Wildermuth, 2002). We present some eco-intensity evaluation methods as potential sustainability indicators for effective environmental management. The novelty of our investigation lies in analyzing detailed energy flow characteristics and in combining energy flow and material flow. Another objective of this paper is to present a current case-study experience in one type of eco-intensity analysis for Japanese service industries.

\section{ECO-INTENSITIES IN VIEWING ENERGY AND MATERIAL FLOWS}

A local city council project aimed to construct material and energy flow analysis models producing an integrated approach to improving overall sustainability (Krrishnamohan et al., 2000). Their analysis highlighted the ultimate fate of inputs, products/services and wastes, and shown crucial help in minimization of resource consumption and/or development of potential synergies between organizations in terms of resource exchange. Beside, a first step was made in bridging the gap between the various types of analysis of material flows in the economy (Bouman et al., 2000), by discussing the main differences and similarities of three often employed model types: substance flow analysis, life cycle assessment and partial economic equilibrium analysis. Consider a kind of "Trilemma" involving the environment, energy, and the 
economy. The following simple equation [Eq.1] shows a way to identify one type of eco-intensity related to energy and material flows:

$$
L_{i}=\frac{L_{i}}{E_{i}} \times \frac{E_{i}}{M_{i}} \times \frac{M_{i}}{P_{i}} \times P_{i}
$$

In this equation, $L_{i}$ is environmental load emissions (e.g., carbon dioxide emission); $E_{i}$ is the energy consumption or primary energy supply; $M_{i}$ is the total material input or requirement; and $P_{i}$ is the gross domestic product or amount of industrial product. Since the eco-intensity should be inversely proportional to the eco-efficiency, any reduction in carbon dioxide emissions with economic growth requires remarkable reductions in three ratios: " $\mathrm{CO}_{2} /$ energy", "energy/flow", and "flow/GDP". These are potential sustainability indicators.

\section{DATA AND METHODS}

We considered sixteen industrial categories (agriculture, mining, food, fiber, pulp, chemical, coal and petrol, cement, steel, metal, nonferrous metals, construction, energy supply, transport, service, and commercial) using data from the national physical distribution census (TERC, 1997), the national and prefectural input-output tables (JSA, 1997), and the comprehensive energy statistics (ANRE, 1997) for Japan in 1995. The objective environmental load items were carbon dioxide, nitric oxide, sulfuric oxide, and suspended particulate matter emissions. Data on these life-cycle environmental emissions are available in the embodied energy and emission intensity database (Nansai et al., 2000) uploaded by the National Institute for Environmental Studies in Japan. The regions studied were all forty-seven Japanese prefectures. The averaged population of a prefecture is about three million and the average area is about 8,000 square kilometers. The major market area is the central zone, which covers about 600 kilometers between Tokyo and Osaka. The prefecture farthest from Tokyo is Okinawa, which is over 2,000 kilometers away.

Figure 1 is a simple outline of the analysis that we used to evaluate regional and industrial eco-efficiency or eco-intensity related to energy and material flow. First, we estimated the primary energy input and material input for each industrial sector in each region. Energy demand consists of the net energy use and energy lost considering generation efficiency and transmission loss. Energy supply consists of the primary energy input and recycled energy recovered. Then, we analyzed relationships between these estimated values to evaluate eco-intensity as sustainability indicators for a region or industry.

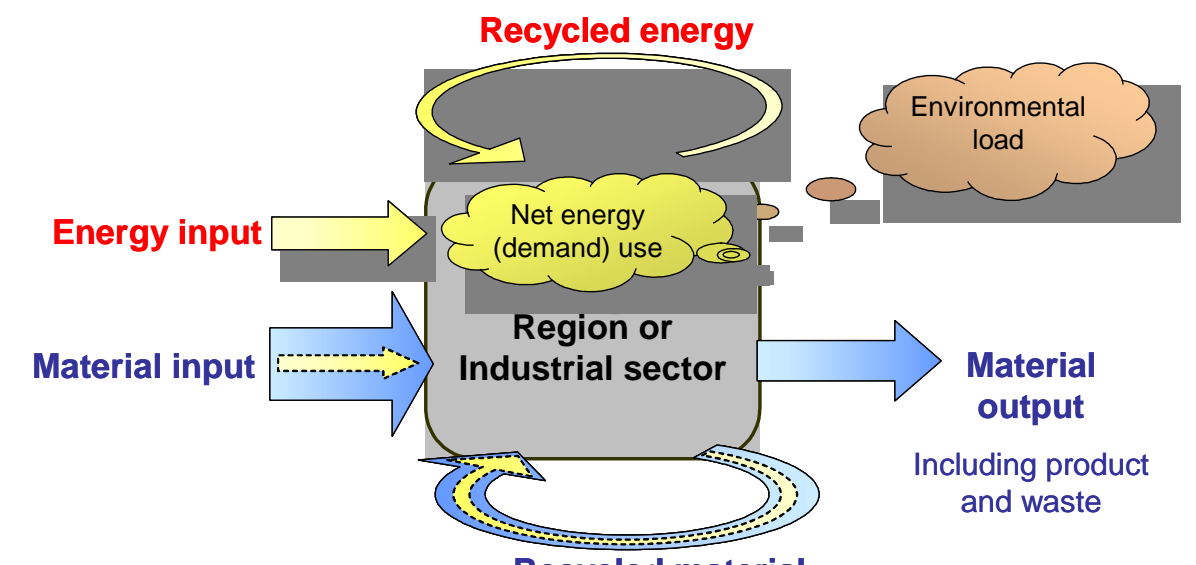

Recycled material

Figure 1 A simple outline of the analysis used to evaluate regional and industrial eco-efficiency or eco-intensity 


\section{THE RATIO OF THE ENVIRONMENTAL LOAD TO ENERGY FLOW \\ AS A MEASURE OF INDUSTRIAL ECO-INTENSITY}

Figure 2 shows the ratio of carbon dioxide emissions to the primary energy input for each industry. These ratios represent the industrial eco-intensity for the entire country. The cement industry has the greatest impact because of the large limestone consumption. Construction also has a major impact because of the ripple effect. For the ratio of nitric oxide emissions to primary energy input (see Figure 3), agriculture and transportation have the greatest effect because of the large amounts of direct emissions via several routes. The ratio of sulfuric oxide and suspended particulate matter to primary energy input showed similar tendencies.

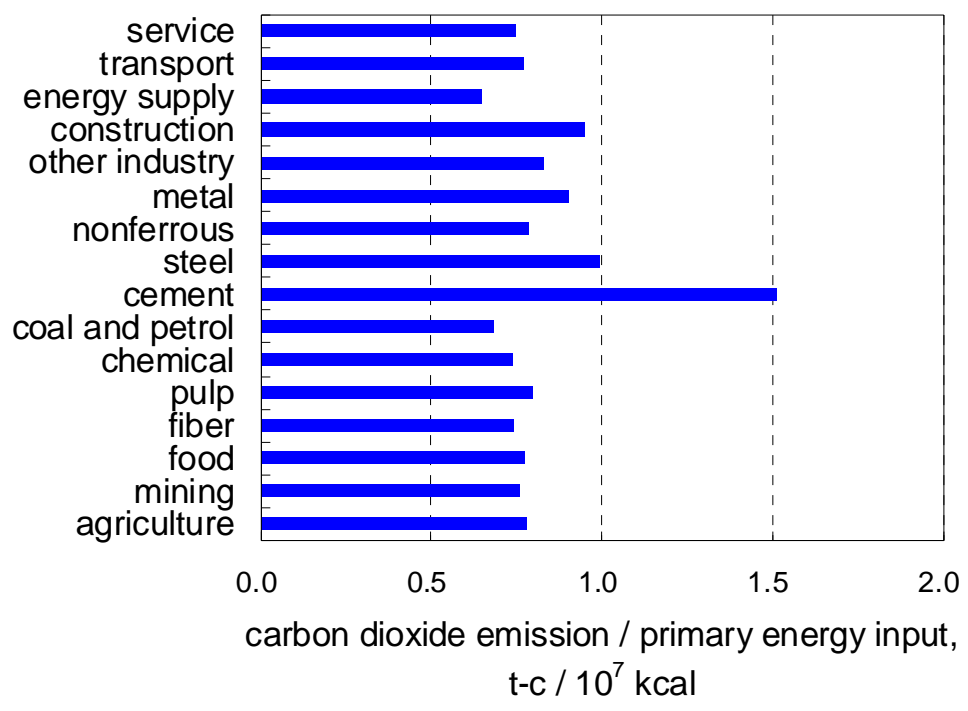

Figure 2 Ratio of carbon dioxide emissions to primary energy input for each industry

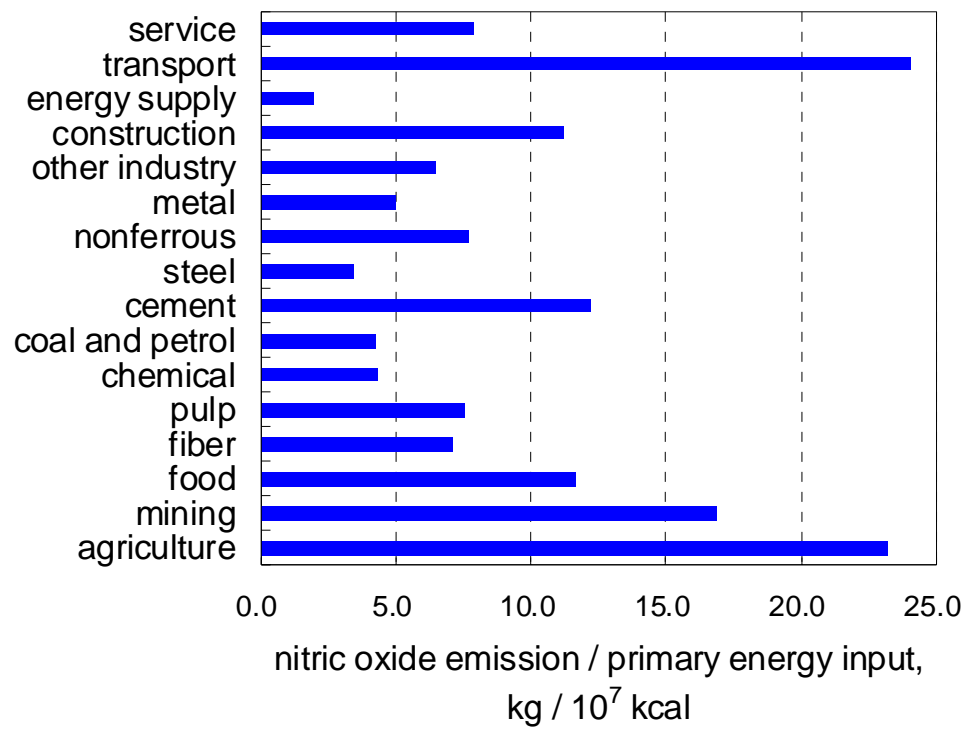

Figure 3 Ratio of nitric oxide emissions to primary energy input for each industry 


\section{THE RATIO OF ENERGY FLOW TO MATERIAL FLOW FOR THE SERVICE INDUSTRY AS A MEASURE OF THE REGIONAL ECO-INTENSITY}

In some cases, the ratio of the energy flow to material flow was investigated as another possible way to evaluate the eco-intensity. This type of indicator is derived by converting mass units into thermal units. We investigated several such combinations, where the energy flow data were estimated as life-cycle values and the material flow data were estimated as direct material input or output without hidden flow.

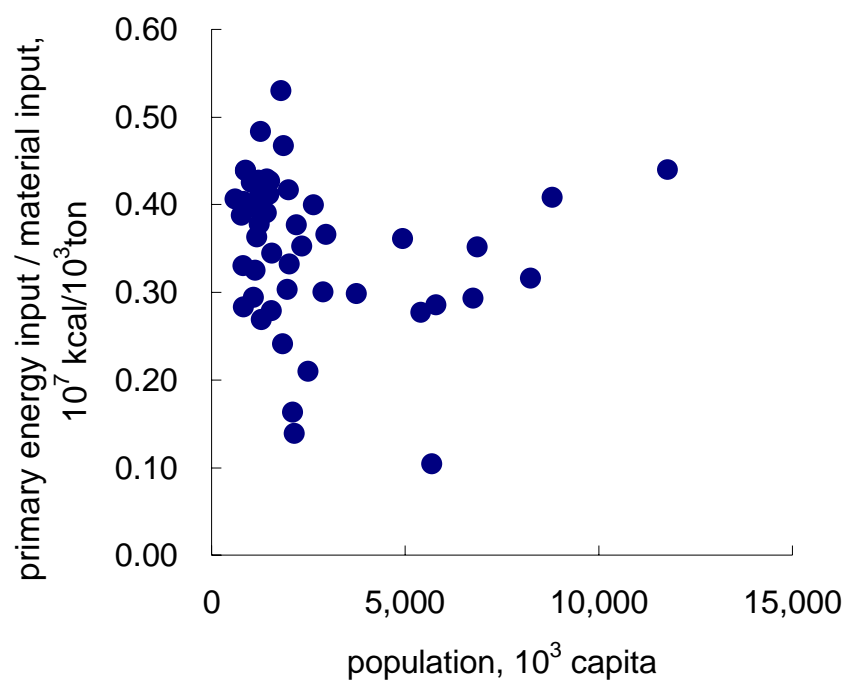

Figure 4 Relationship between the ratio of primary energy input to the total material input of the service industry and population of each prefecture

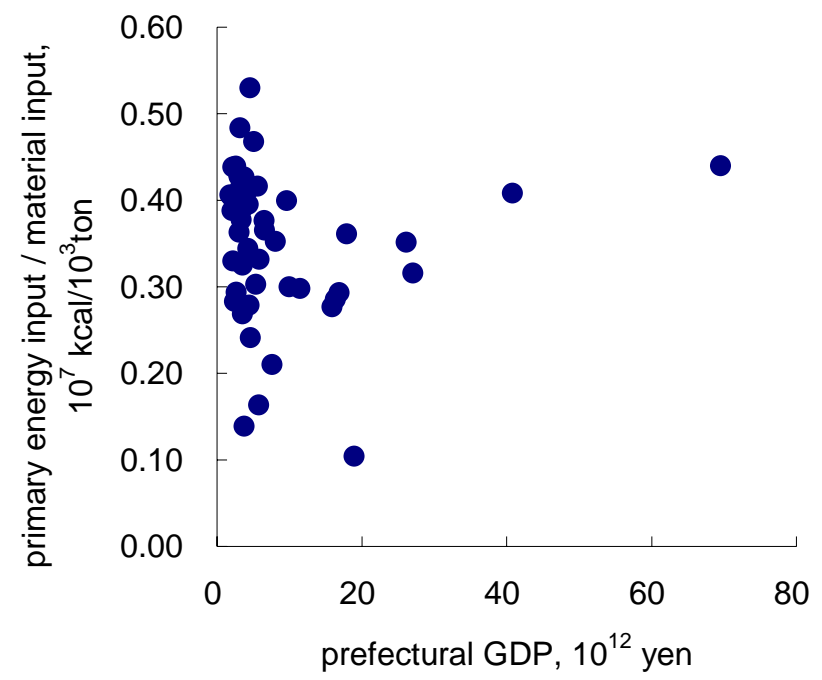

Figure 5 Relationship between the ratio of primary energy input to the total material input of the service industry and the GDP of each prefecture 
The ratio of the primary energy input to the total material input varied significantly between industrial sectors. Focusing on the regional variation in this intensity for the service industry, Figure 4 shows the relationship between the ratio of the primary energy input to the total material input of the service industry and the population of each prefecture. In different prefectures, this ratio ranged from 0.1 to 0.5 . The units of this ratio are the ton oil equivalent [TOE] energy per mass kiloton. This relationship suggests an optimal population size from the perspective of the eco-intensity of the service industry. Figure 5 implies that another relationship gives the optimal economic potential from the perspective of eco-intensity for the service industry. Here, the GDP is the gross domestic product of each prefecture. In this way, several interesting relationships between eco-intensity and regional characteristics, such as the regional population or regional economic potential, were obtained.

The ratio of net energy use to product output also varied significantly between industrial sectors. We compared the regional variation in this intensity for the service and chemical industries. Figure 6 shows the relationship between the ratio of net energy use to product output for the service industry and the distance each prefecture is from Tokyo, which reflects the location of the region with respect to the major market. The ratio of net energy use to product output for the service industry in each prefecture ranged from 0.2 to 1.4. There was an interesting relationship between this ratio and the distance from the major market. This relationship was positive for some industrial sectors and negative for others. Focusing on the service industry, this relationship suggests that the distance from the major market has a negative effect on eco-efficiency. By contrast (see Figure 7), in the chemical industry, this relationship suggests that the distance reduces the eco-intensity or improves the eco-efficiency. This difference might result from differences in site location or the supply chain system for those two industrial categories.

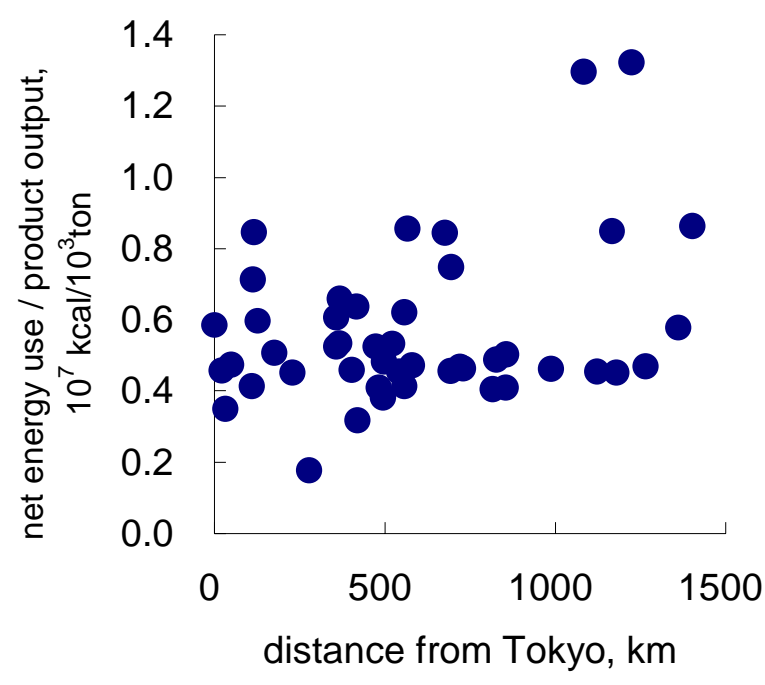

Figure 6 Relationship between the ratio of net energy use to product output for the service industry and the distance of each prefecture from Tokyo 


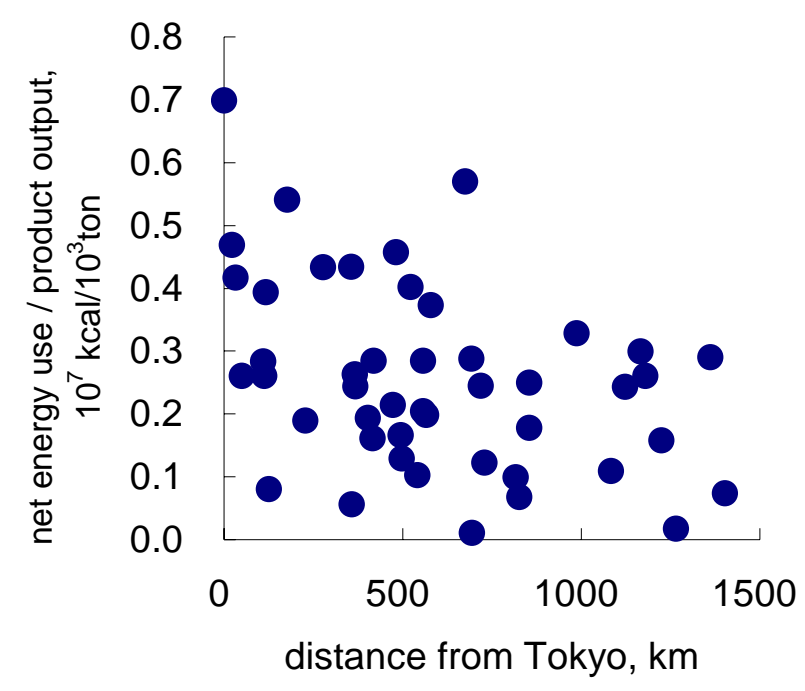

Figure 7 Relationship between the ratio of net energy use to product output for the chemical industry and the distance from Tokyo for each prefecture

\section{CONCLUSIONS}

The authors used simple ratios as sustainability indicators to evaluate the environmental intensity in local regions and industrial sectors. These ratios could be compared across region and industrial sector to give a comprehensive evaluation of sustainability. Several relationships between the ratio of primary energy input to total material input and regional or industrial characteristics were obtained, and these suggested an optimal population size or economic growth potential. Relationships between the ratio of net energy use to product output and regional or industrial characteristics were also obtained, such as the distance from major markets. However, we have not yet examined all the variation in these sustainability indicators and there are likely other complicated relationships between sustainability and regional or industrial characteristics. We need to put more effort into estimating eco-efficiency or eco-intensity considering recycled energy or material utilization in order to develop a practical method of evaluating regional or industrial sustainability.

\section{ACKNOWLEDGMENTS}

The authors thank Agency for Natural Resources and Energy, Japan Statistical Association, Transport Economy Research Center, National Institute for Environmental Studies and other related organizations for providing the valuable digital data used in this study.

\section{REFERENCES}

Adriaanse, A., Bringezu, S., Hammond, A., Moriguchui, Y., Rodenburg, E., Rogich, D. and Scutz, H. (1997), "Resource Flow: The Material Basis of Industrial Economies", World Resources Institute (WRI).

Agency for Natural Resources and Energy in Japan (1997), "Comprehensive Energy Statistics for 1995 in Japan".

Bouman M., Heijungs R., van der Voet E., van den Bergh JCJM and Huppes G. (2000), "Material flows and economic models: an analytical comparison of SFA, LCA and partial equilibrium models", Ecological Economics, Vol.32, pp.195-216. 
Herendeen, R. A. and Wildermuth, T. (2002), " Resource-based sustainability indicators: Chase County, Kansas, as example", Ecological Economics, Vol.42, pp. 243-257.

Japan Statistical Association (1997), "National and Prefectural Input-Output Tables for 1995 in Japan".

Krrishnamohan, K., Scott, A. and Christesen, I. (2000), "Material/Energy Flow Balance Analysis With Life Cycle Assessment For A Large Metropolitan City", International Conference \& Exhibition on Life Cycle Assessment: Tools for Sustainability.

Nansai, K., Moriguchui, Y. and Tohno, K. (2000), "Embodied Energy and Emission Intensity Database", National Institute for Environmental Studies in Japan.

Transport Economy Research Center (1997), "6th Physical Distribution Census in Japan". 